\title{
Chapter 7 \\ Evolving Huawei Framework: SEPs and Grant of Injunctions
}

\author{
Indranath Gupta, Vishwas H. Devaiah, Dipesh A. Jain \\ and Vishal Shrivastava
}

\section{Introduction}

There have been certain developments with the emergence of the European Commission's Communication Paper (EC paper) titled 'Setting out the EU approach to Standard Essential Patents'. ${ }^{1}$ The EC paper, which was addressed to the European Parliament, reflected upon the broad contours of the licensing of standard essential patents (SEPs) in the age of Internet of Things (IoT). It identified the difficult phases including granting of injunctions in the process of licensing the SEPs.

The Huawei case decided by the Court of Justice of the European Union (CJEU) had in fact proposed a framework for the SEP holder before a claim could be raised for an injunction. ${ }^{2}$ The chapter identifies such framework as suggested by CJEU in the Huawei judgement with further reference to cases that have been decided in

\footnotetext{
${ }^{1}$ European Commission, 'Setting out the EU approach to Standard Essential Patents' COM (2017) 712 final (EC Paper) <https://ec.europa.eu/docsroom/documents/26583> accessed 10 January 2018; Roundtable on Digitising European Industry with Commissioner Oettinger (Roundtable) 20 September $2016<$ http://ec.europa.eu/information_society/newsroom/image/document/2016-39/ 160913_background_document_17339.pdf> accessed 10 May 2018.

${ }^{2}$ Case C-170/13 Huawei Technologies Co. Ltd v ZTE Corp. EU:C:2015:477.
}

I. Gupta $(\bowtie) \cdot$ V. H. Devaiah

Jindal Global Law School, OP Jindal Global University, Sonipat, India

e-mail: igupta@jgu.edu.in

V. H. Devaiah

e-mail:vhdevaiah@jgu.edu.in

I. Gupta $\cdot$ V. H. Devaiah $\cdot$ V. Shrivastava

JIRICO, OP Jindal Global University, Sonipat, India

e-mail: vshrivastava@jgu.edu.in

D. A. Jain

Associate, A.V. Jain Associates, Mumbai, India

e-mail: dipesh@avjainassociates.com

(C) The Author(s) 2018

A. Bharadwaj et al. (eds.), Multi-dimensional Approaches Towards New Technology,

https://doi.org/10.1007/978-981-13-1232-8_7 
Germany and in the UK. While there is a general adherence to the framework identified in Huawei, subsequent cases have helped in developing the framework further. There have been cases of inconsistencies and it seems that the issue of overall conduct of the parties in the negotiation process becomes crucial before deciding the grant of injunctions in the licensing of SEPs. Towards that end, the first part of the chapter considers the EC Paper followed by the second part identifying the framework proposed in the Huawei judgement. The third part, which includes cases from Germany and UK, reflects on the changes that are happening in relation to the framework developed in the Huawei judgement.

\section{EC Communication Paper to the European Parliament}

The EC paper was made with the objective of reducing the uncertainty already existing in the current SEP regulatory environment for the development of IoT products in the near future. ${ }^{3}$ The EC paper identified several concerns related to SEPs that require immediate attention so that the potential growth seen in IoT sector is not hindered due to the issues that have emerged in the Information and Communications Technology (ICT) sector. ${ }^{4}$ The EC paper has rightly pointed out that these uncertainties would be sensitive given that 'players coming from new industrial sectors' emerge as they would have no prior experience of dealing in ICT technologies. 5

As per the EC paper, the unclear and diverging interpretations of fair, reasonable, and non-discriminatory (FRAND) hampered the licensing process. ${ }^{6}$ Moreover, there is a need to provide a stable licensing environment to be able to guide parties in their negotiations. ${ }^{7}$ The EC paper identifies negotiations in SEP licensing as an important step in furthering the above objectives. ${ }^{8}$ Any potential delay in such negotiations might delay the use of standard technologies. This may result in hampering the development of interconnected products in Europe further affecting the competitiveness of the European Union's (EU) economy. Failed negotiation is one of the major reasons for the increase in SEP disputes.

To this end, the EC paper discussed inter alia the obligations cast upon parties during pre-licensing negotiations for licensing of SEPs on FRAND terms. ${ }^{9}$ The EC paper has derived such obligations from the behavioral criteria as determined in the Huawei judgement. ${ }^{10}$ The EC paper provides that parties are best placed to arrive at

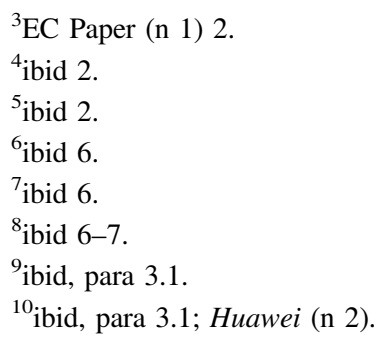


a common understanding of what are fair licensing conditions and fair rates by indulging in good faith negotiations. ${ }^{11}$

\section{Steps Prior to Granting Injunctions in SEP Cases}

In case the parties are not able to negotiate a licensing deal and at the same time, the implementer continues to make use of the SEPs, then the SEP holder, having left with no other option, would most likely file a case seeking an injunction on the infringement and for appropriate royalty. Further, the implementers might take a defense that the SEP holder is abusing his dominant position in the market. The courts will then have to rule on these issues while assessing the negotiations that took place between the SEP holder and implementer.

\subsection{The Huawei Guidelines}

The CJEU in Huawei talks about the ideal behavior of SEP holder and implementer in negotiation process. ${ }^{12}$ The case sets out certain expectations, which an SEP holder is expected to follow before making itself eligible to file an action for seeking injunction for patent infringement or for recall of products against the alleged infringer without violating Article 102 of TFEU. ${ }^{13}$ In the process, Huawei also recommends the standards implementer to follow certain steps before relying on the plea of abuse of dominant position by the SEP holder. The Huawei case has only provided instances where the actions of the SEP holder will amount to an abuse and it does not go beyond that. ${ }^{14}$ The CJEU has failed to take into consideration the possibility that the SEP holder might be abusing its dominant position even if it notifies the implementer. ${ }^{15}$

At the outset, the patent holder should raise a complaint about the infringement by notifying the implementer about the SEPs that are infringed and the manner in which they are infringed (Notice Stage). ${ }^{16}$ As a second step, the SEP holder should present a specific offer to the implementer to conclude a licensing agreement on FRAND terms including amount of royalty and details of its calculations (Offer stage). ${ }^{17}$ This step is subject to express willingness on the part of the implementer to

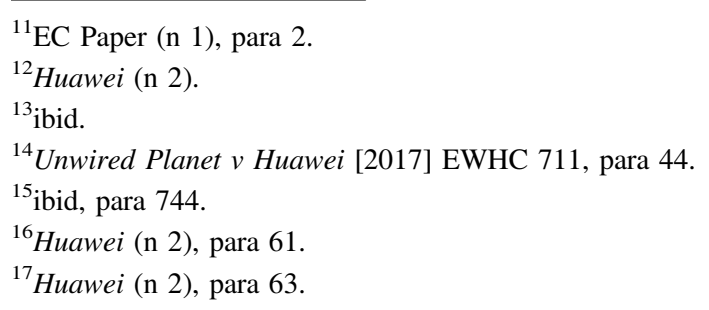


enter into negotiations with the SEP holder and conclude the licensing agreement on FRAND terms. ${ }^{18}$

As a third step, the implementer should respond to the specific offer extended by SEP holder in good faith and in a diligent manner, keeping in mind the recognized commercial practices, thereby refraining from any delaying tactics (Response Stage). ${ }^{19}$ Such response can be in the form of an acceptance, enquiry, counter offer or rejection.

The fourth step provides that in case the implementer wants to rely on 'abusive nature of an action of prohibitory injunction or for the recall of products', it can do so but only after it has submitted to the SEP holder, a specific counter offer that corresponds to FRAND terms (Counter offer stage). ${ }^{20}$ If the implementer has been using the SEP before a licensing agreement has been concluded, then it should provide appropriate security, in accordance with the recognized commercial practices from the point when its counter offer was rejected. ${ }^{21}$

If the parties fail to reach an agreement on FRAND terms, they may decide to approach an independent third party for determining the amount of royalty. ${ }^{22}$

While the Huawei ruling offered a general framework of expectations, there were issues, which remained unanswered requiring further clarifications.

The Huawei ruling recommended the SEP holder to make an offer to a willing implementer to take the license on FRAND terms. Consequently, if the implementer shows unwillingness, then the SEP holder would have no other choice but to file a legal action for infringement and other necessary remedies such as recall of products, unpaid royalties, or for determination of royalty rates by court. The point of contention in many cases have been the reasonable period within which the communication of willingness by an implementer is expected. Huawei also left unclear as to what would constitute adequate or sufficient willingness.

At the stage of extending an offer, the contents of such offer should relate to the undertaking given to an SSO. For instance, the European Telecommunications Standards Institute's (ETSI) Intellectual Property Rights Policy requires SEP holder to sign an undertaking stating that it is prepared to license the patents included in the standard on FRAND terms to willing licensees. ${ }^{23}$ Additionally, Huawei requires an offer to specify the amount of royalty and details mentioning the calculation of royalty rates. ${ }^{24}$ The judgement does not provide much clarity about the extent of comprehensiveness of information present in such offer.

\footnotetext{
${ }^{18}$ Huawei (n 2), para 63.

${ }^{19}$ Huawei (n 2), para 65.

${ }^{20}$ Huawei (n 2), para 67.

21 ibid.

${ }^{22}$ Huawei (n 2), para 68.

${ }^{23}$ European Telecommunications Standards Institute, 'ETSI Intellectual Property Rights Policy' (2017) <http://www.etsi.org/images/files/ipr/etsi-ipr-policy.pdf> accessed 10 May 2018.

${ }^{24}$ Huawei (n 2), para 63.
} 
At the stage of responding to the offer, going by recognized commercial practices the response of an implementer can range from (i) accepting the offer as it is, (ii) rejecting the offer, (iii) making further enquiries or negotiating an NDA or pricing, and (iv) making a counter offer. It may be implied from Huawei that an implementer opting for any of the four steps must do so (i) diligently, (ii) in accordance with recognized commercial practices in the industry, (iii) in good faith, and (iv) without adopting any delaying tactic. ${ }^{25}$ Huawei specifies that in case the implementer chooses to reject the offer made by the SEP holder, it must make a specific counter offer on FRAND terms to defend itself from future legal actions initiated by the SEP holder. ${ }^{26}$ In this context, even while making enquiries about the offer extended by the SEP holder there is ample opportunity for an implementer of technology to prolong the whole process of negotiation by using dilatory conduct.

In a commercial transaction, there can be multiple cycles of offer, counter offers or enquiries before an agreement can be reached between the parties. However, this aspect of business negotiation was not considered in Huawei.

Some of the above issues were taken up and discussed by the courts in the member states. Part 3.2 discusses the clarifications and different interpretations emerging from post-Huawei cases in Germany.

\subsection{Implementation of Huawei Guidelines in Subsequent SEP Cases}

Huawei judgement resulted when the Dusseldorf court wanted a clarification from the CJEU about existing standards in form of the Orange Book Standard ${ }^{27}$ or the more advanced approach set by the European Commission in its Samsung and Motorola decisions. ${ }^{28}$

\footnotetext{
25 “... it is for the alleged infringer diligently to respond to that offer in accordance with recognized commercial practices in the field and in good faith, a point which must be established on the basis of objective factors and which implies, in particular, that there are no delaying tactics"; Huawei (n 2), para 65 .

${ }^{26}$ Huawei (n 2), para 66.

${ }^{27}$ Case No. KZR 39/06O Orange-Book-Standard Bundesgerichtshof, Judgement dated 6 May 2009.

${ }^{28} \mathrm{C}(2014) 2891$ final Case AT.39939-Samsung-Enforcement of UMTS standard essential patents, European Commission's decision dated 29 April 2014; C(2014) 2892 final Case AT.39985-Motorola-Enforcement of GPRS standard essential patents, European Commission's decision dated 29 April 2014.
} 
The Huawei guidelines covering the concept of willingness and negotiation process have been considered in several cases in Germany. ${ }^{29}$ Courts in Germany have considered the obligations expressed under Huawei and broadly looked at the steps of the negotiation process. The Regional Court in Dusseldorf provided that action of notice is to be understood as service by which information about subsequent legal action is given. It does not depend on the submission but on the service of the action. ${ }^{30}$ Although the decision provided by the CJEU in Huawei provides a general framework for SEP owners looking for injunctive relief, overall, the decision has led to various interpretations by German courts because of absence of precise direction or formal requirements in the Huawei framework.

The first step under the Huawei framework is to ensure that SEP holders reach out to the implementer or alleged infringer and inform them regarding their acts of infringement. ${ }^{31}$ The German courts in cases like Pioneer v Acer, ${ }^{32}$ Saint Lawrence $v$ Vodafone ${ }^{33}$ Sisvel v Haier,${ }^{34}$ granted SEP holders a 'transition time period' as these were the cases, which were filed prior to the decision in Huawei, during which the SEP holders did not apply the formal requirements of Huawei. ${ }^{35}$ In such 'transitional cases', the infringement notice, even though served later after the complaint for infringement was filed, would be considered as sufficient notice. It was the reasoning of German courts that it would be wrong to retrospectively fault the SEP holder for not having given notice, and where the parties have progressed to offer and counter offer steps. ${ }^{36}$ The notice is served for informational purpose and in transitional cases, the courts found the knowledge of implementer about SEP was undisputable at a stage where the legal proceedings have already started. ${ }^{37}$

The Dusseldorf court in Pioneer v Acer suggested that the Huawei framework should not be understood as a purely formal criteria, but as a behavioral test to

\footnotetext{
${ }^{29}$ Case No. 4a O 93/14 Sisvel v Haier (2015) LG Dusseldorf; Case No. 2 O 106/14 Saint Lawrence $v$ Deutsche Telekom (2015) LG Mannheim; Case No. 4a O 74/14 Saint Lawrence v Vodafone (2016) LG Dusseldorf; Case No. 7 O 66/15 NTT DoCoMo v HTC (2016) LG Mannheim; Case No. 7 O 96/14 Pioneer v Acer (2016) LG Mannheim, Judgement dated 8 January 2016; Case No. 7 209/15 Philips v Archos (2016) LG Mannheim.

${ }^{30}$ Case No. 4a O 126/14 Saint Lawrence v Vodafone LG Dusseldorf, Judgement dated 31 March 2016, para 35 .

${ }^{31}$ Huawei (n 2), para 61.

${ }^{32}$ Pioneer (n 29), para 94.

${ }^{33}$ Saint Lawrence (n 30), para 232.

${ }^{34}$ Case No. 4a O 144/14 Sisvel v Haier (2015) LG Dusseldorf, Judgement dated 3 November 2015, 29.

${ }^{35}$ Pioneer (n 29); Saint Lawrence (n 29); Sisvel (n 34).

${ }^{36}$ Jorge Contreras, The Cambridge Handbook of Technical Standardization Law (Cambridge University Press 2017) 427.

${ }^{37}$ ibid 427.
} 
ensure that the parties, which assert themselves to be willing to license or take a license under FRAND conditions verbally, are serious. ${ }^{38}$

The Huawei guidelines covering the concept of willingness and negotiation process have been considered in several cases in Germany.

The German courts have clarified the requirement of notice of infringement. The LG Mannheim court in NTT DoCoMo and Pioneer suggested that the SEP holder should inform the implementer about the infringement by way of identifying and specifying the SEPs in question. ${ }^{39}$ The Regional Court in NTT DoCoMo notes that the notice must make it clear to the implementer about the standard and the circumstances leading up to the infringement. ${ }^{40}$ The court also remarked that the details of a notice can be decided on a case-by-case basis. ${ }^{41}$ With regard to the information relating to the SEP in question, the Dusseldorf court in Saint Lawrence $v$ Vodafone suggested that at least the publication number of the patent in dispute and the alleged use should be mentioned in the notice. ${ }^{42}$ The Dusseldorf court further stated that, to comply with the Huawei framework relating to the requirement of notice of infringement 'before bringing the action', the SEP holder must send such a notice before the filing of the claim, and at least before the advance payment on costs has been made by the SEP holder to the court for the injunction. ${ }^{43}$

Once the SEP holder has given notice to the implementer, it becomes the duty of the implementer then to respond to that notice and show willingness to engage in negotiations to obtain a license. Such response must be given within a reasonable period. In cases like Saint Lawrence v Deutsche Telekom, Sisvel v Haier and Saint Lawrence $v$ Vodafone, the court took note of the time taken to respond to the notice from the SEP holder. ${ }^{44}$ In Deutsche Telekom, the court ruled that the period of more than three months was too long for showing willingness to license. ${ }^{45}$ Further, in Saint Lawrence $v$ Vodafone, it was the Regional Court's view that the implementer is required to declare his willingness to enter into a licensing agreement immediately and in this situation, the delay of five months was considered too long. ${ }^{46}$ The Regional Court in Saint Lawrence v Vodafone also suggested that the timeline before declaring a licensee 'unwilling' will depend on specific circumstances of a case and the information given by the SEP holder in the notice of infringement must also be taken into account. ${ }^{47}$ For instance, the expectation of timely response to declare 'willingness' by an implementer would depend on the details provided in the notice

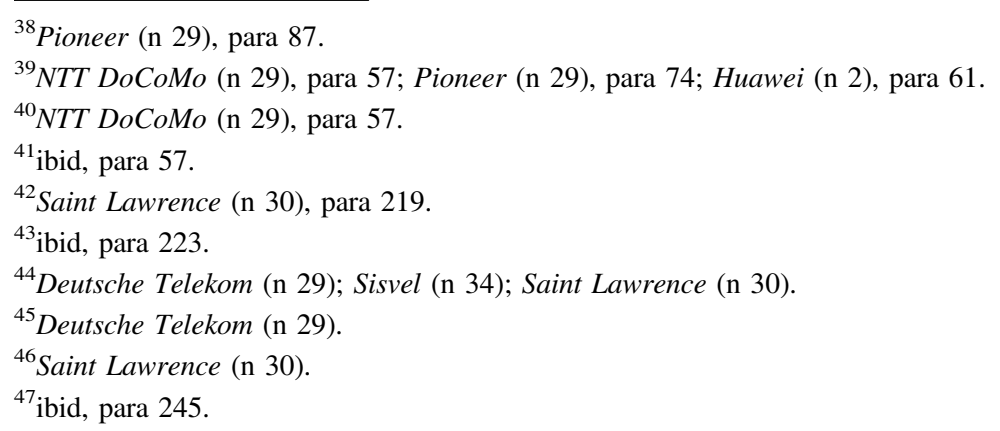


of infringement. ${ }^{48}$ In Pioneer $v$ Acer, the court suggested that the overall behavior of the implementer or its parent company was not favorable to the Huawei guideline. ${ }^{49}$ In Sisvel v Haier, the Higher Regional Court decided that the question of willingness should be decided bearing in mind the licensee's overall conduct during the licensing procedure. ${ }^{50}$ Once the implementer gives adequate and unconditional willingness to take a licence on FRAND terms, it is for the SEP holder to provide to the implementer an offer containing the royalty and details of its calculations. ${ }^{51}$

The Regional Court of Dusseldorf, while determining whether the offer given by an SEP holder corresponds to FRAND terms, held that comparable license agreements are a significant indicator of the adequacy of offered license conditions. Similarities in licensing conditions create a stronger presumption that royalties offered by the SEP holder complied with FRAND requirement. ${ }^{52}$ The courts have favored looking at the licenses of same quality and scope to make a comparison of the FRAND aspect of the offer. On the issue of royalty rate the Regional Court in Saint Lawrence v Vodafone further stated that there is no need for the SEP holder to provide a mathematical derivation of the royalties, as there is no single royalty that is solely considered as FRAND, rather a range of values will be fair, equitable and non-discriminatory. ${ }^{53} \mathrm{It}$ must be sufficient for the SEP holder to specify the essential considerations that constitute the licensing fees. ${ }^{54}$ According to the Higher Regional Court of Karlsruhe, the SEP owner has a wide discretion in determining the FRAND conditions. ${ }^{55}$ The court in Philips, provides that an offer cannot be termed as FRAND if the method of calculation of royalties is not comprehensible. ${ }^{56}$

Once the SEP holder has issued an offer, which encompass FRAND norm, it is the duty of the implementer to react promptly without adopting any delaying tactics. ${ }^{57}$ The Regional Court of Mannheim in Pioneer provides that the implementer must react to an offer, even if it does not comply with FRAND norm. ${ }^{58}$ In some instances, the courts have refused to determine whether the offer made to an implementer followed the FRAND norm when the implementer has failed to demonstrate willingness to conclude the license on FRAND terms. ${ }^{59}$ A similar approach was adopted in Sisvel v Haier. ${ }^{60}$ The courts have decided Sisvel $v$ Haier

\footnotetext{
48 ibid, para 252.

${ }^{49}$ Pioneer (n 29).

${ }^{50}$ Case No. I-15 U 66/15 Sisvel v Haier OLG Dusseldorf, Judgement dated 13 January 2016.

${ }^{51}$ Huawei (n 2), para 63.

${ }^{52}$ Saint Lawrence (n 30), para 267.

53 ibid, para 314.

${ }^{54}$ ibid, para 313.

${ }^{55}$ Case No. 6 U 58/16 2016, OLG Karlsruhe Resolution of 8 September 2016, para 36.

${ }^{56}$ Philips (n 29), para 112.

${ }^{57}$ Huawei (n 2), para 65.

${ }^{58}$ Pioneer (n 29), para 77.

${ }^{59}$ ibid; Sisvel (n 34).

${ }^{60}$ Sisvel (n 34) 30.
} 
based on the response of the parties by looking into their behavior or on the nature of response given by the implementer. In Saint Lawrence v Deutsche Telekom, the court ruled that a restrictive counter offer would not correspond with FRAND conditions because the implementer instead of responding to the offer for a worldwide license, restricted its offer only to Germany. ${ }^{61}$ In fact, the absence of an indication of the royalty rate in the counter offer will not constitute a concrete counter offer'. ${ }^{62}$ The reasoning behind such qualification as given by the Mannheim Regional court is that the implementer will not be able to furnish guarantee during the negotiations because of absence of a fixed rate. ${ }^{63}$ The court in NTT DoCoMo $v$ $H T C$ considered that the implementer failed in its obligation to react by means of a written counter offer as it was sent more than one and a half years after the SEP holder had sent the offer. ${ }^{64}$

Negotiation is a continuous process and there need not be a counter offer directly after an offer is made by the SEP holder. There could be a possible stage where an implementer can raise an inquiry on the offer of SEP holder or out rightly reject the offer. The Huawei guidelines provide that if the SEP holder rejects the counter offer of the implementer, the latter must deposit appropriate security, in accordance with recognized commercial practices. ${ }^{65}$ Following the Huawei guidelines, there have been instances where the courts have highlighted the importance of depositing appropriate security to the SEP holder within reasonable time. In Sisvel v Haier, the court took note of the fact that even after the rejection of counter offer the implementer never rendered an account on a timely basis or provided security as per the Huawei guidelines. ${ }^{66}$ The court was of the view that by merely providing counter offers, implementers are not absolved from their responsibilities towards the SEP holder. ${ }^{67}$ This obligation arises from the point when the first counter offer is rejected. ${ }^{68}$ The court in the Sisvel case considered that a time of around one year from the rejection of the counter offer was late for providing security and rendering of accounts. The court recommended that the Huawei requirement 'from the time its counteroffer was rejected' must be interpreted in a narrow manner. ${ }^{69}$ A delay in rendering of accounts and security seems to be an expression of delaying tactic. ${ }^{70}$ In Pioneer, the court stated that the implementer must show all seriousness towards

\footnotetext{
${ }^{61}$ Deutsche (n 29), para 59.

${ }^{62}$ ibid, para 59.

${ }^{63}$ ibid, para 232.

${ }^{64}$ NTT DoCoMo (n 29), para 73.

${ }^{65}$ Huawei (n 2), para 67.

${ }^{66}$ Sisvel (n 34) 33.

${ }^{67}$ ibid 33.

68 ibid 32.

${ }^{69}$ ibid 33.

${ }^{70}$ ibid 33.
} 
taking the license. ${ }^{71}$ This includes providing security, which is necessary after the rejection of the counter offer and may result in invalidating antitrust claims.

\subsection{The Judgement in Unwired Planet}

Unwired Planet $v$ Huawei has tried to deal with unresolved FRAND issues and competition concerns in SEP licensing disputes. ${ }^{72}$ The court dealt with abuse of dominant allegations against the SEP holders in the market by assessing the FRAND licensing terms and by proceeding with the ambitious task of determining a global FRAND royalty rate. The court while trying to assess FRAND stated that determining what a willing licensor and a willing licensee should do in the relevant circumstances would help in deciding the question. Justice Birss has termed the entire concept of FRAND as a process and discussed the pre-licensing behaviour of licensing parties. He stated that FRAND commitment requires the SEP holder to behave in particular ways. $^{73}$

According to Unwired Planet, the Huawei requirement of 'willingness' to enter into a license refers to an unqualified willingness. ${ }^{74}$ Justice Birss stated that Huawei requires a willing licensee to show unqualified willingness to take a FRAND license on terms that would constitute as FRAND. ${ }^{75}$

At the offer stage, the Huawei guidelines require that the SEP holder should make an offer containing the exact calculation of royalty rate. ${ }^{76}$ The decision in Unwired Planet case provides that it would not be a case of abuse of dominant position, if the rates offered were not FRAND. The reasons given by the court were threefold. The first reason was that the offers were made in the process of negotiation and as per the court's observation it is a common market practice to initiate negotiations at a higher rate so that the license can be concluded at a lower rate. ${ }^{77}$ The court observed that a very high rate would force the implementer to refuse to negotiate further. ${ }^{78}$ This observation was different from what happened in Huawei as Huawei did not deal with SEP holder providing a non-FRAND rate. The second reason is that offers were not significantly higher than FRAND. ${ }^{79}$ The court

\footnotetext{
${ }^{71}$ Pioneer (n 29), para 87.

${ }^{72}$ Unwired Planet (n 14).

${ }^{73}$ ibid, para 162.

${ }^{74}$ ibid, para 708 .

75 ibid, para 708 .

${ }^{76}$ Huawei (n 2), para 63.

${ }^{77}$ Unwired Planet (n 14), para 163.

78 ibid, para 163.

${ }^{79}$ ibid, paras 163-164.
} 
provided the third reason that there was no economic evidence and analysis of distortion of competition in the market. ${ }^{80}$

Further, insistence by an implementer on a license that is limited to a single territory will not be FRAND compliant. ${ }^{81}$ FRAND is a process and in every case, there is only one set of terms which comply with FRAND. The rates offered by the SEP holders are usually 'higher' than the FRAND rate but this approach is not always abusive because there is a legitimate expectation that during the negotiation process the rates may change. ${ }^{82}$

The Unwired case has further clarified the meaning associated with FRAND royalty rate and abuse of dominant position. There have been contentious issues about offering license to implementers based on worldwide portfolio. ${ }^{83}$ Justice Birss said that asking an implementer to accept a worldwide license would not be considered abusive, as it has efficiency benefits and given the fact that calculation of SEP portfolio values on a country-by-country basis would involve complexities. ${ }^{84}$

\section{Conclusion}

Licensing of SEPs can be foreseen as a major concern in the background of emerging IoT products and services. SEP holders, after the failure of licensing negotiations seek injunctive relief against the implementer. This threat of injunctive relief becomes the basis for an antitrust complaint by the implementers. To invalidate such antitrust concerns, there is an emerging jurisprudence requiring parties to take certain precautions.

The Huawei case developed a framework to deal with the general behavior of the parties that ought to be followed in pre-licensing negotiations of SEPs. Further clarifications have emerged from the post-Huawei cases in Germany and in the UK. As an obvious outcome of an evolving jurisprudence, courts in different jurisdictions have not been able to fix an objective framework which may be used in latter cases. From the perceived inconsistences, it seems that the overall conduct of the parties would play a major role before granting injunctive relief to SEP holders. The Huawei framework, however, provided enough freedom to maneuver and steer future cases towards a far more objective approach.

\footnotetext{
${ }^{80}$ ibid, para 670 .

${ }^{81}$ ibid, para 572 .

82 ibid 162.

${ }^{83}$ ibid, para 535.

${ }^{84}$ ibid, para 544 .
} 
Disclosure Opinions expressed in the work are independent of any research grants received from governmental, intergovernmental and private organisations. The authors' opinions are personal, and are based upon their research findings and do not reflect the opinions of their institutional affiliations.

Open Access This chapter is licensed under the terms of the Creative Commons Attribution 4.0 International License (http://creativecommons.org/licenses/by/4.0/), which permits use, sharing, adaptation, distribution and reproduction in any medium or format, as long as you give appropriate credit to the original author(s) and the source, provide a link to the Creative Commons license and indicate if changes were made.

The images or other third party material in this chapter are included in the chapter's Creative Commons license, unless indicated otherwise in a credit line to the material. If material is not included in the chapter's Creative Commons license and your intended use is not permitted by statutory regulation or exceeds the permitted use, you will need to obtain permission directly from the copyright holder.

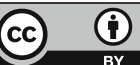

